\title{
Association between Fruit Development and Mature Fruit Drop in Huanglongbing-affected Sweet Orange
}

\author{
Lisa Tang, Sukhdeep Singh, and Tripti Vashisth \\ Citrus Research and Education Center, University of Florida, Institute of \\ Food and Agricultural Sciences, 700 Experiment Station Road, Lake Alfred, \\ FL 33850
}

Additional index words. Candidatus Liberibacter asiaticus, preharvest fruit drop, fruit abscission, phloem plugging, tree water status, fruit size

\begin{abstract}
In the past decade, FL citrus industry has been struck by Huanglongbing (HLB), a disease caused by the phloem-limited bacterium Candidatus Liberibacter asiaticus ( $C$ Las). Besides tree decline, HLB causes a sharp increase in mature fruit drop before harvest, leading to a substantial reduction in citrus production. The aim of the study was to provide insights in HLB-associated mature fruit drop. For HLB-affected 'Valencia' and 'Hamlin' sweet orange (Citrus sinensis), trees exhibiting severe symptoms ("severe trees") had a significantly higher rate of mature fruit drop compared with mildly symptomatic ones ("mild trees"). Interestingly, dropped fruit were smaller than those still attached to tree branches regardless of the symptom levels of trees; overall, fruit of severe trees were smaller than mild trees. The result suggests a negative effect of HLB on fruit growth that may lead to a high incidence to drop subsequently at maturity. This possibility is further supported by the difference in immature fruit size as early as 2 months after bloom between severe and mild trees. Although HLB-triggered phloem plugging due to callose deposition in citrus leaves, which results in disrupted carbohydrate transport, has been documented in literature, the results of the histological analysis demonstrated no consistent pattern of callose deposition in the mature fruit pedicel in relation to the drop incidence. Additionally, sugar concentration in juice was not significantly different between dropped and attached fruit, providing evidence that carbohydrate shortage is not the case for dropped fruit and thus not the predominant cause of HLB-associated mature fruit drop. Notably, the midday water potential was significantly lower for severe than mild trees during the preharvest period ( 2 weeks before harvest of the current crop) in late March, which was also the second week after full bloom of return flowering. This suggests that altered tree water status due to HLB might limit fruit growth during the initial stage of fruit development (immediately after flowering) and/or increase the incidence of mature fruit abscission, leading to elevated preharvest fruit drop. Together, the results suggest that in the presence of HLB, strategies to increase fruit size and minimize additional stresses (especially drought) for the trees may improve mature fruit retention.
\end{abstract}

Huanglongbing, or citrus greening, was first discovered in Florida in 2005 (Halbert, 2005). Since then, it has spread across the state and caused a dramatic economical loss due to the reduction in citrus yield and deterioration of trees (Alvarez et al., 2016;

Received for publication 12 Feb. 2020. Accepted for publication 26 Mar. 2020.

Published online 24 April 2020

We thank Dr. Christopher Vincent for the equipment for water potential measurement, Tony Trama for the technical support with carbohydrate quantification, and Daniel Stanton for his assistance with microscopy work. The acknowledgment is also extended to Taylor S. Livingston for the technical assistance in carbohydrate analysis and field-related activities.

L.T. and S.S. contributed equally.

T.V. is the corresponding author. E-mail: tvashisth@ ufl.edu.

This is an open access article distributed under the CC BY-NC-ND license (https://creativecommons. org/licenses/by-nc-nd/4.0/).
Halbert, 2005). During the 2018-19 production season, total production of citrus in Florida was 77 million boxes ( 3.4 million tons), less than one-third of the citrus production in the pre-HLB era of the 2003-04 season (292 million boxes; 13.0 million tons) (USDA, 2019).

Candidatus Liberibacter asiaticus, the causal agent of HLB, is a phloem-restricted bacterium transmitted by an insect vector, asian citrus psyllid (Diaphorina citri) (Halbert et al., 2000; Jagoueix et al., 1994). Shortly after being infected with CLas, citrus trees undergo a decline in root system, and the symptoms develop subsequently in the canopy, including a blotchy mottle on leaf blades and twig dieback, as well as small and lopsided fruit with poor juice quality (Baldwin et al., 2010; Bové, 2006; Johnson et al., 2014). Furthermore, HLB increases the incidence of preharvest fruit drop, which refers to the abscission of physiologically mature fruit (at the stage III of fruit development) occurring $\approx 3$ months before commer- cial harvest (Albrigo and Stover, 2015; Bové, 2006; Iglesias et al., 2007). Under field conditions, the fruit drop rate of sweet orange trees exhibiting severe HLB symptoms was significantly higher than that of mildly symptomatic trees starting at 3 months before harvest, suggesting a strong correlation between HLB severity and mature fruit drop in disease-affected citrus trees (Tang et al., 2019). In addition to the reduction in the harvestable crop on trees due to excessive fruit drop, citrus growers lose extra revenue for the cost and efforts that have been put in throughout fruit production and grove management. At present, the applications of plant growth regulators that effectively improve fruit retention in healthy citrus trees do not consistently demonstrate positive results on the control of fruit drop in HLB-affected 'Valencia' and 'Hamlin' sweet orange trees (Albrigo and Stover, 2015). Because the cure for HLB has yet to be developed, the clarification of the mechanism that underlies how HLB increases mature fruit abscission can be a key for the development of strategies to mitigate HLB-associated preharvest drop and thereby improve the yields.

The increased occurrence of sieve pore plugging and phloem collapse in leaf midribs has been documented in HLB-affected citrus compared with healthy (CLas-negative) citrus (Deng et al., 2019; Etxeberria et al., 2009; Kim et al., 2008), along with the accumulation of sucrose in leaves (Kim et al., 2008). It has therefore been hypothesized that limited carbohydrate levels in mature fruit, because of disrupted sugar transport due to blocked phloem, may be the cause of mature fruit abscission associated with HLB. This proposed mode of action of HLB-related mature fruit drop is analogous to that of the abscission of immature citrus fruit around 2 months after anthesis, or known as "June drop," due to the competition for finite amount of carbohydrates among developing fruit (Goldschmidt, 1999; Goldschmidt and Monselise, 1977; Gómez-Cadenas et al., 2000; Ruiz et al., 2001). Nonetheless, for HLB-affected 'Valencia' sweet orange, mature fruit that were highly inclined to drop (requiring force $<6 \mathrm{kgF}$ to be removed from the tree branch) did not have less carbohydrates compared with fruit clinging tightly to branches (requiring force $>6 \mathrm{kgF}$ to be detached) (Tang et al., 2019). This result provides evidence that, in contrast to the prevalent hypothesis, low carbohydrate availability in mature fruit does not correspond to a high tendency to abscise during the preharvest period. It is also worth noting that mature fruit of severely symptomatic trees were smaller and had a low detachment force (a higher dropping tendency) compared with those of trees displaying mild HLB symptoms (Tang et al., 2019).

Currently, how HLB elevates the physiological drop of mature citrus fruit is not completely understood. In HLB-affected trees, internal water relations might be altered because of the loss of feeder roots (Hamido et al., 2017; Johnson et al., 2014). 
It is relevant to this research that water-deficit stress not only causes a reduction in fruit mass (García-Tejero et al., 2010; Pérez-Pérez et al., 2009) but also triggers fruit abscission (Ginestar and Castel, 1996; Romero et al., 2006) for healthy citrus trees. Therefore, whether HLB has a negative impact on tree water status, thereby increasing fruit drop before harvest, warrants investigation.

Given the correlation between mature fruit size and detachment force demonstrated previously by Tang et al. (2019), the first objective of this research was to confirm the link between fruit abscission and fruit size in relation to HLB severity. The fruit drop rates in trees exhibiting different levels of visual HLB symptoms under field conditions as well as the characteristics of dropped and attached (mature) fruit were compared in early-maturing 'Hamlin' and late-maturing 'Valencia' sweet orange, two primary cultivars for juice production in Florida. A subsidiary goal was to verify whether carbohydrate stress, presumably due to the increased incidence of phloem plugging by callose deposition (triggered by CLas infection) is the case in fruit that drop before harvest. Thus, the carbohydrate concentrations in juice and the level of callose deposition in the pedicel of dropped and attached fruit were quantified. The second objective of the current study was to determine the effect of HLB on tree water status in association with fruit size and abscission. The water potential of severe and mild sweet orange trees was therefore assessed at the stage of early fruit development and during the preharvest period.

\section{Materials and Methods}

Plant materials. Currently, healthy citrus trees (with undetectable CLas level) are rarely present in open-air groves due to the prevalence of HLB in Florida. Therefore, sweet orange trees that exhibited different levels of HLB symptoms based on the rating system developed by the Citrus Research and Development Foundation (Lake Alfred, FL) described by Slinski (2016) were selected to differentiate the effects of different degrees of HLB severity in this research. All citrus trees, including 18-year-old 'Valencia' and 17-year-old 'Hamlin' sweet orange on 'Swingle' citrumelo (C. paradisi $\times$ Poncirus trifoliata), in the current research were located in the experimental orchards at the University of Florida Citrus Research and Education Center in Lake Alfred.

Experimental design and sample collection of Expt. 1. The purpose of Expt. 1 was to determine the relationship between the fruit size and physiological drop of mature fruit in response to HLB. Thus, the effects of HLB severity as well as the attributes associated with drop incidence were compared in attached and dropped fruit of mild, moderate, and severe trees (six combinations in total). The drop rate was assessed in late-maturing 'Valencia' sweet orange trees for two separate production seasons (years 1 and 2) and early-maturing 'Hamlin' sweet orange for a year ( $n=4$ in all cases). Before fruit drop assessment, any existing dropped fruit on the orchard floor were removed; 80 branches bearing single fruit at the distal position were tagged per tree for the subsequent collection of tissues and physical trait data in case of dropped fruit. During the 3-month preharvest period, the number of dropped fruit on the orchard floor was recorded every $3 \mathrm{~d}$. The duration of survey for each sweet orange cultivar was listed as follows: from 27 Jan. to 28 Apr. 2017 and 4 Feb. to 22 May 2019 as years 1 and 2, respectively, for Valencia; from 2 Oct. through 4 Dec. 2018 for Hamlin. Total drop rate was calculated as the cumulative dropped fruit number divided by the total fruit number (the sum of dropped fruit and attached fruit on trees at harvest). It should be noted that the physiological abscission of mature fruit was of research interest. Thus, only the dropped fruit displaying no visible symptoms of other pests and pathogens, such as stem-end rot (caused by Lasiodiplodia theobromae) and canker (caused by Xanthomonas citri subsp. citri), were taken into account for sample collection (Supplemental Fig. 1).

For each of the six combinations of fruit type based on drop incidence (attached or dropped fruit) and tree HLB symptom level (mild, moderate, or severe), the transverse diameter of fruit was measured with an electronic caliper to represent fruit size; the number of leathery mature (source) leaves on the $20-\mathrm{cm}$-long fruit-bearing branches were counted as well as the number of seeds inside the mature fruit. For 'Valencia' sweet orange in year 1 , juice was extracted from fruit by hand and stored at $-20{ }^{\circ} \mathrm{C}$ for carbohydrate analysis; pedicels along with the calyx abscission zone (AZ), where mature fruit drop takes place, were excised at $\approx 0.5$ $\mathrm{cm}$ from fruit for callose quantification, using microscopy.

Quantification of carbohydrates in juice. The concentration of total soluble solids (TSS) in juice of 'Valencia' sweet orange in Expt. 1 was determined using a handheld refractometer (Pocket PAL-BX1 ACID1; Atago USA, Bellevue, WA). The concentrations of sucrose, fructose, and glucose were quantified using ion chromatography (IC). Following centrifugation at $12,000 g_{\mathrm{n}}$ for 5 min, the supernatant of juice samples was filtered through a prefilled chromatography column (1-X8 resin; Bio-Rad, Hercules, CA) to remove anion contaminates and then transferred to a polytetrafluoroethylene filter vial $(0.45 \mu \mathrm{m}$; Restek, Bellafonte, PA) for another filtration. The elute was injected into an IC equipped with an anion exchange column and a guard column (CarboPac PA200; Dionex, Sunnyvale, CA). An isocratic mobile phase consisting of solvent A (95\% deionized water) and solvent $\mathrm{B}, 5 \% \mathrm{NaOH}(1 \mathrm{~N})$-with a flow rate of $0.4 \mathrm{~mL}$ per minute-was used. Standard curves for sucrose, fructose, and glucose were made and used for quantification, respectively.
Quantification of callose deposition in fruit peduncles. Immediately after excision, pedicel-AZ tissues of 'Valencia' sweet orange in Expt. 1 were fixed in a FAA solution (10\% formalin, $5 \%$ acetic acid, and $50 \%$ ethanol, v/v) and stored at $4{ }^{\circ} \mathrm{C}$ until further use. Two samples from each replicate were used in this study. After removal from the FAA solution, samples were rinsed thoroughly in deionized water and dehydrated by sequential transfer through an ascending ethanol series $(60 \%, 70 \%$, $85 \%$, and $95 \%$ ethanol). Paraffin infiltration and embedding were performed as described by Ruzin (1999). Subsequently, paraffin blocks were sectioned longitudinally $(10 \mu \mathrm{m})$ using a microtome (RM 2155; Leica, Buffalo Grove, IL), followed by the staining with $0.01 \%(\mathrm{w} / \mathrm{v})$ aniline blue for callose. Images were captured using a 14-megapixel charge-coupled device digital camera (OMAX, Irvine, CA) attached to an epifluorescence microscope (BX61; Olympus, Center Valley, PA). Fluorescence intensity for callose deposition was analyzed using ImageJ software (Easlon and Bloom, 2014; Schneider et al., 2012). Corrected total cell fluorescence (CTCF) was calculated, as described by Gavet and Pines (2010) and $\mathrm{Gu}$ et al. (2016), as follows: CTCF $=$ integrated density $-($ area of selection $\times$ mean fluorescence of background readings).

Experimental design and water potential measurement of Expt. 2. In Expt. 2, to determine whether HLB has an effect on fruit growth during early development, the size of 50 attached, immature fruit of mild and severe trees of 'Valencia' sweet orange $(\mathrm{n}=$ 5) were measured in May (about 9 weeks after full bloom). Between 1000 and $1100 \mathrm{HR}$, four fully expanded leaves were detached from each tree and quickly preserved in a sealed ziplock bag with a moist paper towel in a chest cooler. Midday leaf water potential was assessed in the laboratory, using a water potentiometer (WP4; Decagon Devices, Inc., Pullman, WA) according to the manufacturer's manual and description by Fan et al. (2015). Average monthly precipitation of the last decade (2009-19) were obtained from the Florida Automated Weather Station Network located at Lake Alfred, FL.

To further investigate the influence of HLB on tree water status related to fruit drop during the preharvest period, the size of 15 mature fruit that remained on branches of mild and severe trees of 'Valencia' sweet orange $(n=5)$ was recorded in March (2 weeks before harvest), which also happened to be the second week following full bloom of the return (spring) flowering. Meanwhile, midday water potential was quantified onsite between 1000 and $1200 \mathrm{HR}$ on five fully expanded leaves per tree with a Scholander pressure chamber (PMS Instrument Company, Albany, OR). The disparity of the approaches used for water status evaluation during early fruit development vs. preharvest period was simply due to the availability of the equipment. 
Statistical analysis. Two-way analysis of variance (ANOVA) was used to determine the effects of fruit types (attached or dropped fruit), tree symptom levels of HLB (mild, moderate, or severe trees), and their interaction on total drop rate of mature fruit, fruit physical characteristics, juice carbohydrate concentrations, and callose deposition level in Expt. 1, using the General Linear Model procedure of SAS software (version 9.3; SAS Institute, Cary, NC); when ANOVA testing indicated significant differences, post-hoc comparisons were run using Tukey's honestly significant difference procedure with a family error rate of $\alpha \leq 0.05$. Student's $t$ test was used to test for the difference in fruit size and midday leaf water potential between mild and severe 'Valencia' sweet orange trees in Expt. 2.

\section{Results and Discussion}

Mature fruit drop in trees with different HLB symptom levels. During the preharvest period ( 3 months before harvest) in year 1 of the survey, 'Valencia' sweet orange trees exhibiting severe HLB symptoms had a significantly greater drop rate of mature fruit than mildly symptomatic trees (Fig. 1), indicating that mature fruit drop is dependent on HLB severity in affected citrus trees. A similar pattern was also present in 'Valencia' sweet orange in year 2 , as well as in the early-maturing cultivar Hamlin, in which the total drop rate of mature fruit was the highest for severe trees and lowest for mild trees (Fig. 1). The increase in mature fruit drop with the progression of HLB symptoms in sweet orange trees observed in this study is consistent with the record of elevated fruit drop over time as HLB becomes epidemic throughout Florida, reported by the U.S. Department of Agriculture (USDA, 2019). Similarly, the results of a recent study also demonstrated a correlation between the degree of HLB severity and the number of mature fruit, with a high tendency to drop for field-grown 'Valencia' sweet orange trees (Tang et al., 2019).

Carbohydrate availability in fruit and callose deposition. Regardless the HLB symptom levels, the concentration of total soluble solid, sucrose, glucose, and fructose in juice of dropped fruit was not significantly different from attached fruit in 'Valencia' sweet orange trees (Fig. 2), indicating fruit that dropped did not accumulate less carbohydrates compared with those remaining on the tree branch. In other words, carbohydrate shortage was not observed in dropped fruit and thus was not the cause, at least not primarily, of elevated mature fruit abscission related to HLB. In parallel, among the mature fruit that were still attached to HLB-affected 'Valencia' sweet orange trees, loosely attached fruit (requiring force $<6 \mathrm{kgF}$ to be detached; likely to drop) had either greater or similar concentration of sucrose, glucose, and fructose in juice compared with tightly attached fruit (requiring force $>6 \mathrm{kgF}$ to be detached; with a low tendency to abscise) (Tang et al., 2019). This finding suggests no correlation between carbohydrate availability in mature citrus fruit and their inclination to drop associated with HLB. Additionally, the level of callose in the phloem of pedicels of dropped fruit - which is synthesized and accumulated at the sieve pore of phloem in leaves as a consequence of CLas infection (Achor et al., 2010; Kim et al., 2008)—was not greater than that of attached fruit (Fig. 3). This indicates that phloem blockage, which can result in disrupted carbohydrate flow from the source (leaf) to sink (fruit) (Etxeberria et al., 2009; Kim et al., 2008), was not at a greater extent for dropped fruit compared with attached ones, lending further support to the interpretation that carbohydrate stress is not the predominant cause of HLB-related mature fruit drop. Nevertheless, it is possible that partial phloem blockage in the pedicel of dropped fruit observed in this study limits the translocation of other metabolites, such as endogenous plant hormones
(Martinelli et al., 2012; Nehela et al., 2018; Rosales and Burns, 2011), that might have a role in the regulations of fruit abscission in response to HLB.

Reportedly, phloem plugging in leaf midrib is more prominent for citrus cultivars that are highly susceptible to HLB compared with those relatively tolerant to the disease in the presence of CLas (Deng et al., 2019). However, the extent of blockage in phloem of fruit pedicels, indicated by the level of callose deposition (Fig. 3), was not in proportion to the level of HLB symptoms exhibited by 'Valencia' sweet orange trees in the current study. Given the unevenly distributed nature of CLas within the affected trees (Folimonova et al., 2009), the variability in HLB-caused physiological responses may be responsible for the unexpected observation. It should also be noted that the result presented herein does not rule out the possibility that a greater degree of sieve pore plugging or collapse of phloem can take place in other sections of the tree branch.

Physical characteristics related to drop incidence or disease severity. For the 'Valencia' and 'Hamlin' sweet orange trees in this study, the number of mature (source) leaves on fruit-bearing branches was independent of the HLB symptom level (Fig. 4). Although the number of total source leaves per branch was significantly greater for attached fruit than dropped fruit in 'Valencia' sweet orange in year 1 , this pattern was not observed in year 2 or for 'Hamlin' sweet orange (Fig. 4). In addition, the number of symptomatic (blotchy mottled) and asymptomatic leaves and leaf chlorophyll content (data not shown) were not different between attached and dropped fruit in either sweet orange cultivar. Together, the results provide no evidence that supports a correlation between leaf photosynthesis capacity, at least during preharvest period, and HLB-associated mature fruit abscission. Whereas seeds are generally considered as a source of auxin and gibberellic acid that act in opposition to abscission

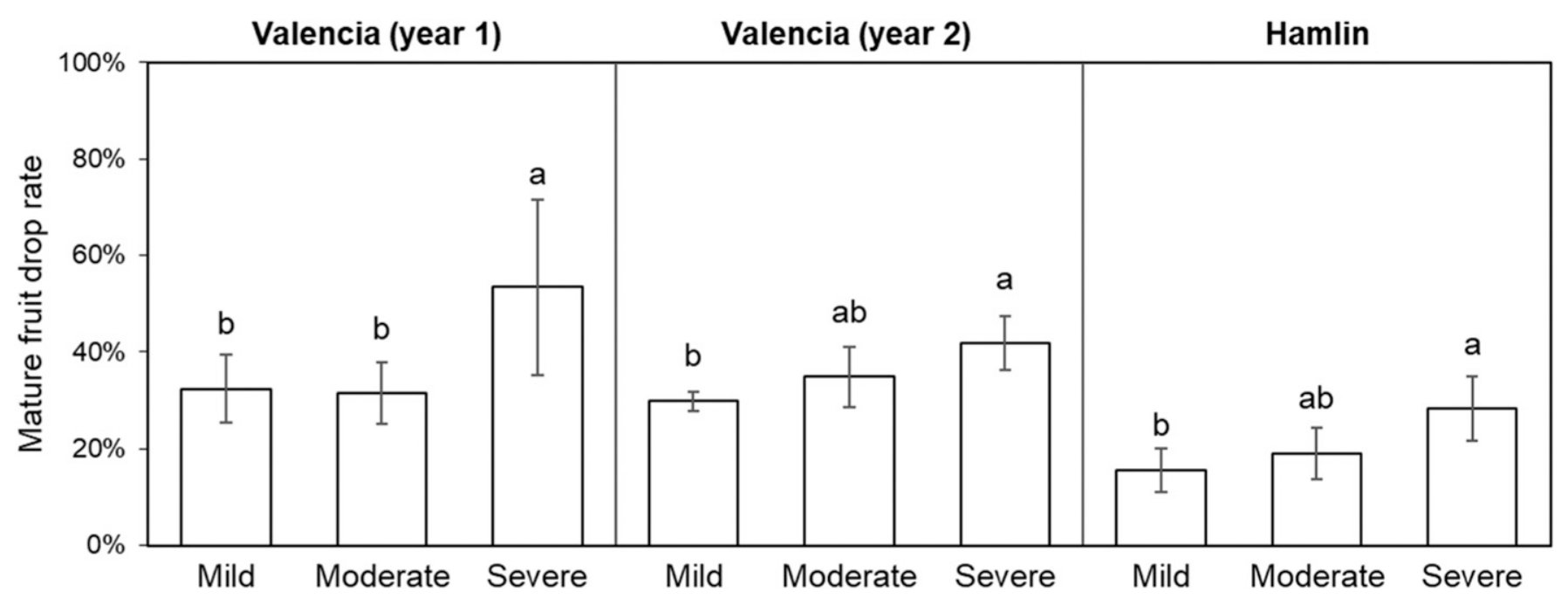

Fig. 1. Total drop rate of mature fruit of 'Valencia' and 'Hamlin' sweet orange trees exhibiting mild, moderate, and severe symptoms of Huanglongbing. Data are means \pm SD of four biological replicates. Different letters in each panel indicate significant difference based on Tukey's honestly significant difference test. 

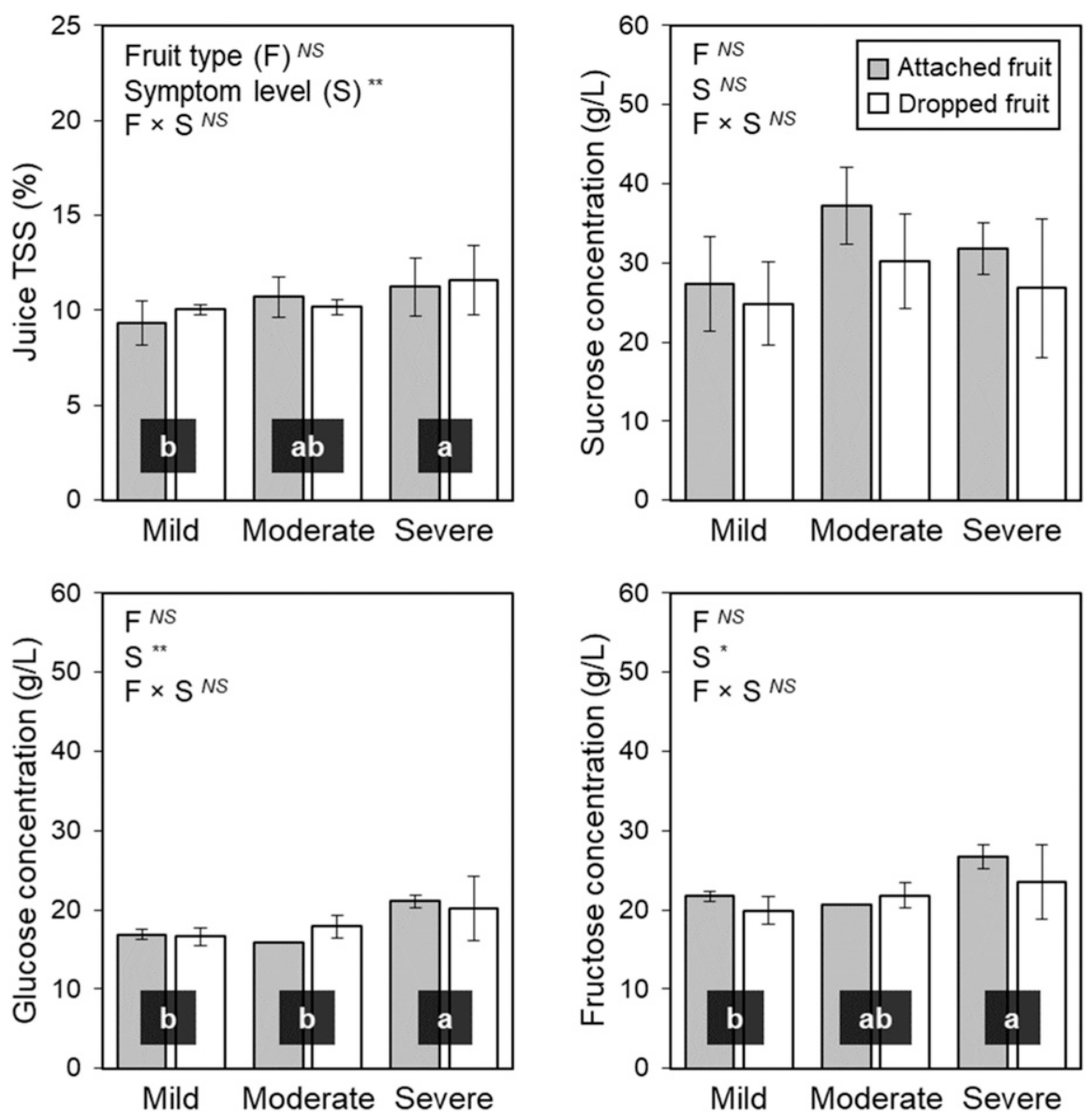

Fig. 2. The concentration of total soluble solid (TSS), sucrose, glucose, and fructose in juice of attached and dropped mature fruit of 'Valencia' sweet orange trees exhibiting mild, moderate, and severe symptoms of Huanglongbing. Data are means \pm SD of four biological replicates. In each panel, different lowercase and uppercase letters indicate significant difference among symptom levels and between fruit types, respectively, based on Tukey's honestly significant difference test. $N S=$ not significantly different.

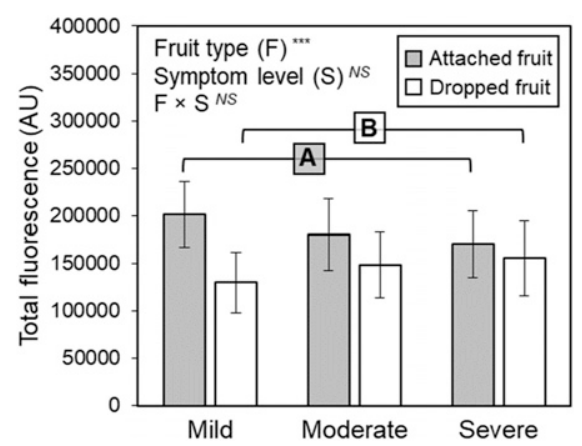

Fig. 3. The level of callose deposition, represented by the corrected total cell fluorescence, in the pedicel of attached and dropped mature fruit of 'Valencia' sweet orange trees exhibiting mild, moderate, and severe symptoms of Huanglongbing. Data are means $\pm S D$ of four biological replicates. Different lowercase and uppercase letters indicate significant difference among symptom levels and between fruit types, respectively, based on Tukey's honestly significant difference test. $N S=$ not significantly different.

(Bangerth, 2009; Crane, 1964; Goren and Huberman, 1976; Iglesias et al., 2007), there was no consistent pattern of total seed number in relation to fruit type or tree symptom level in either sweet orange cultivar (Fig. 4). Thus, the involvement of seed-derived hormones in HLB-associated fruit drop still awaits determination.

$A$ link between fruit size and $H L B-$ associated fruit drop. It is noteworthy that among all physical traits of fruit assessed in this research, the size of mature fruit was the only attribute that was distinguishable between the two types of fruit and among HLB symptom levels in both 'Valencia' and 'Hamlin' sweet orange (Fig. 4). In all cases presented herein, mature fruit of severe trees were significantly smaller than fruit of mild trees. This finding is consistent with the known effect of HLB on fruit size observed in disease-affected trees compared with healthy (CLas-negative) trees (Baldwin et al., 2018; Bové, 2006; Liao and Burns, 2012; Spann and Oswalt, 2008). Moreover, dropped fruit were significantly smaller than attached fruit, irrespective of HLB symptom levels in all instances (Fig. 4). For example, for 'Valencia' sweet orange in year 1, the size of attached and dropped fruit was 64.4 and $61.5 \mathrm{~mm}$, respectively $(P<0.01)$. It should be noted that the parameter used to represent size, transverse diameter of fruit, can be responsible for the small difference in fruit size $(<10 \%)$. Additionally, there was a significant difference in fresh weight of attached and dropped fruit (152.8 and $128.7 \mathrm{~g}$, respectively, $P<0.05$ ) (data not shown), demonstrating that the fruit retained on the sweet orange trees through harvest were indeed larger than those that dropped. The results indicate that the occurrence of abscission, namely the case of dropped fruit, was not caused by a higher gravitational pull (due to a greater fruit mass or size) in comparison with attached fruit. Instead, the results provide evidence suggesting that the HLB-associated reduction in fruit size decreases the potential of mature fruit to stay on trees.

The size of citrus fruit can be attributed to cell division at the stage I of fruit development (the first 2 months following the fruit set) and cell enlargement at the stage II (for 4-6 months thereafter), which increase the number and size of cells, respectively (Ferguson and Grafton-Cardwell, 2014; Iglesias et al., 2007). Therefore, the results of the current study suggest that CLas infection likely has an adverse effect on fruit growth during early developmental stages that leads to an increased incidence of abscission when fruit are physiologically mature. This inference is in agreement with the observation of a low number of hypodermal cells in peels of mature fruit of HLB-affected 'Valencia' sweet orange trees that were smaller compared with fruit of healthy trees (Rosales and Burns, 2011), which suggests cell division may be impeded in response to HLB. Consistently, the results of the current research demonstrated that as early as in May ( 9 weeks after full bloom), immature fruit of severe trees were already significantly smaller than those of mild trees of 'Valencia' sweet orange (Fig. 5), providing strong evidence that fruit growth is restrained by HLB.

Tree water status in relation to $H L B$ severity. In citrus, water accumulates in cells that leads to a rapid increase in fruit size during stage II of fruit development (Coggins, 1986; García-Tejero et al., 2010; Iglesias et al., 2007). It is of relevance that HLB-affected trees undergo a substantial root loss (Graham et al., 2013; Johnson et al., 2014), which may limit the uptake of water (Hamido et al., 2017) that can be used for cell expansion and thereby restrict fruit growth. Nonetheless, during the rapid fruit growth period in May, leaf water potential of 'Valencia' sweet orange trees exhibiting severe HLB symptoms $(-1.8 \mathrm{MPa})$ was not distinguishable from that of mild trees $(-1.8$ $\mathrm{MPa}$ ) (Fig. 5). Notably, immature fruit of mild and severe trees already differed in size in May (Fig. 5), suggesting that the HLBcaused events that lead to restrained fruit growth might have taken place earlier than the time of the water status evaluation reported here. Thus, the results of this study do not exclude the possibility that restricted water uptake owing to HLB-triggered root decline may affect fruit growth after bloom (within about 2 months of fruit set). The lack of correlation between the HLB severity and water potential in May is also likely because 

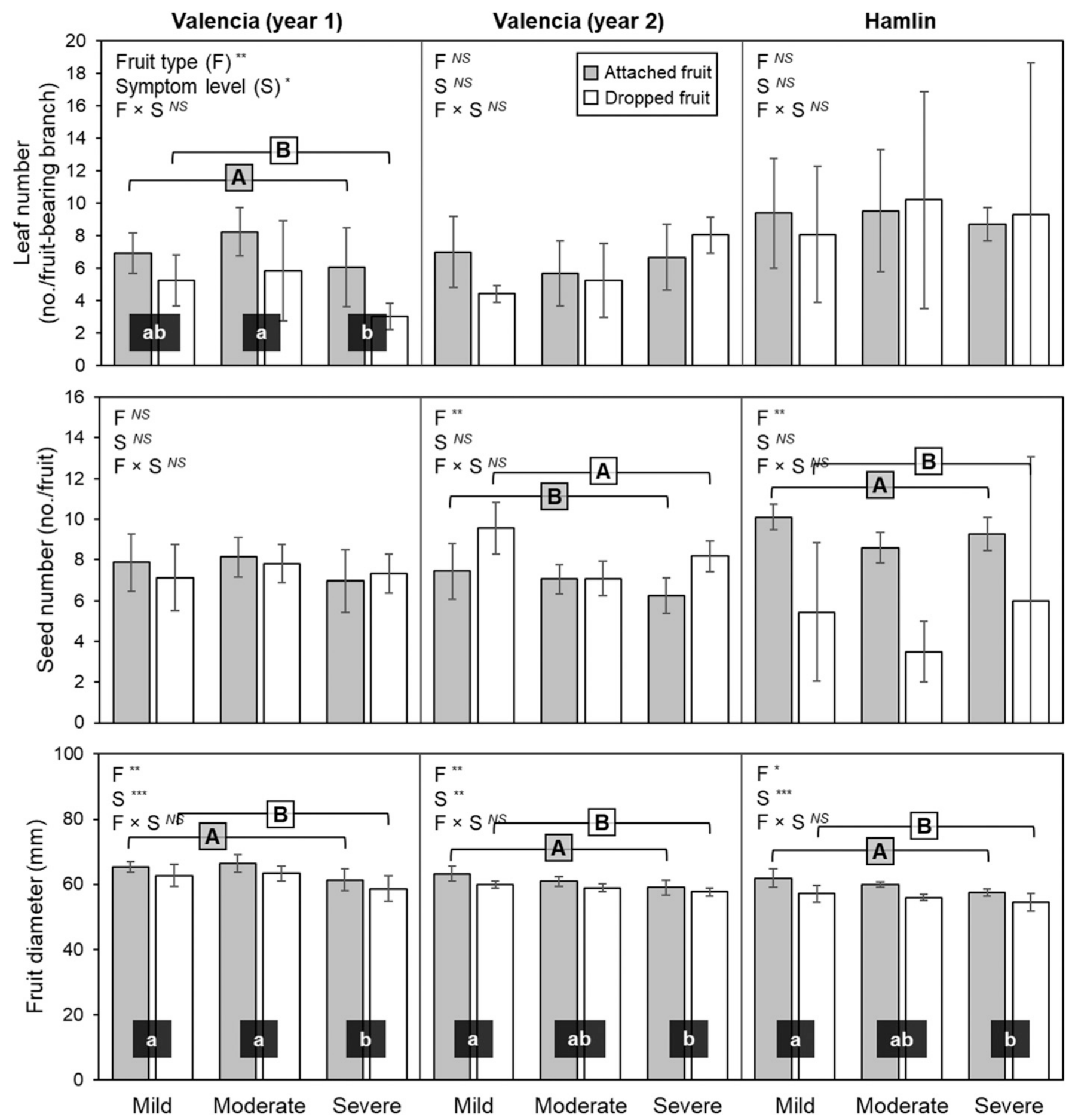

Fig. 4. The number of mature leaves on fruit-bearing branches, number of seeds, and fruit diameter for attached and dropped fruit of 'Valencia' and 'Hamlin' sweet orange trees exhibiting mild, moderate, and severe symptoms of Huanglongbing. Data are means \pm SD of four biological replicates. In each panel, different lowercase and uppercase letters indicate significant difference among symptom levels and between fruit types, respectively, based on Tukey's honestly significant difference test. $N S=$ not significantly different.

of the beginning of the wet season in Florida (Supplemental Fig. 2).

Interestingly, the dry season in Florida, which typically takes place October through May as a result of limited rainfall, overlaps the preharvest period in sweet orange trees (Supplemental Fig. 2). Relevantly, it is welldocumented that for healthy citrus trees, the unfavorable environmental conditions, such as high temperatures, excessive salinity, nu- trient deficient, and drought, accelerate mature fruit drop (Ferguson and GraftonCardwell, 2014; Iglesias et al., 2007; Romero et al., 2006). It is therefore possible that in the spring, little rainfall and warm temperatures (in conjunction with HLB-caused root dieback) subject HLB-affected trees to a stress condition that exacerbates fruit drop. In support of this possibility, the results of the current research demonstrated that midday water potential was significantly lower in severe trees than in mild trees in late March ( 2 weeks before harvest of the current crop) for field-grown 'Valencia' sweet orange (Fig. 6). Meanwhile, mature fruit of severe trees were significantly smaller than those of mild trees, consistent with the observations during the fruit drop surveys (Expt. 1) of this research. Even though the value of water potential in severe trees $(-1.4 \mathrm{MPa})$ reported 

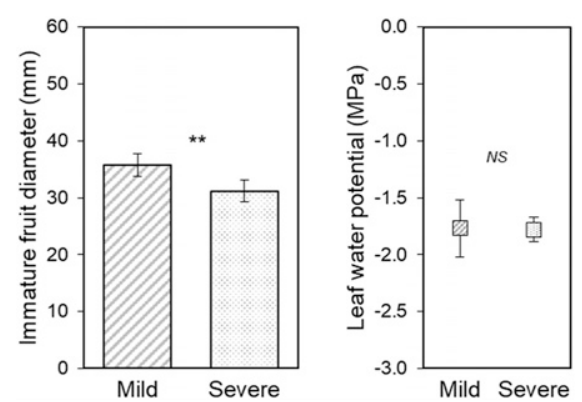

Fig. 5. The size of attached immature fruit and midday leaf water potential of 'Valencia' sweet orange trees exhibiting mild and severe symptoms of Huanglongbing in May (about 9 weeks after full bloom). Data are means \pm SD of five biological replicates. Asterisks indicate significant difference between two symptom levels based on Student's $t$ test. $N S=$ not significantly different.
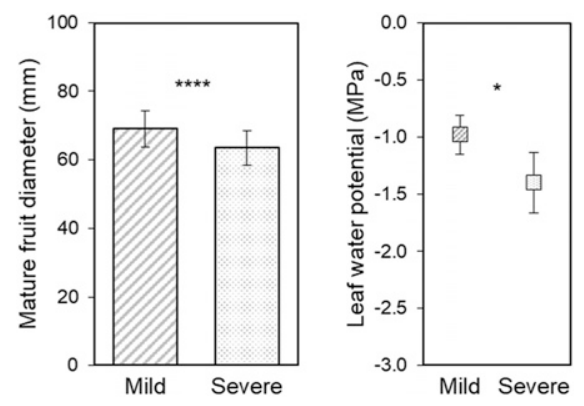

Fig. 6. The size of attached mature fruit and midday leaf water potential of 'Valencia' sweet orange trees exhibiting mild and severe symptoms of Huanglongbing in March (2 weeks before harvest). Data are means \pm SD of five biological replicates. Asterisks indicate significant difference between two symptom levels based on Student's $t$ test.

herein is not in the range of water-deficit stress for citrus [around $-2.0 \mathrm{MPa}$ (Gasque et al., 2016; Syvertsen and Albrigo, 1980)], there is an implication that HLB may alter the tree water status that potentially elevates the incidence of mature fruit abscission.

It should be noted that the assessment of water relation of mature fruit-bearing trees before harvest coincided with the second week following the full bloom of return flowering (Supplemental Fig. 2), which was responsible for the crop the following year. There was also an overlap of dry season and the first two months of fruit development. Taken together, the result demonstrating differential water potential in relation to HLB severity in March (Fig. 6) supports the possibility that initial fruit development immediately after flowering may be negatively affected because of changes in water status of sweet orange trees affected by HLB. To address the question of whether limited fruit growth is because of the decrease in water uptake in HLB-affected trees and thereby increases the incidence of mature fruit drop subsequently, research that continuously monitors the changes in fruit size and tree water status as early as the start of fruit set with preharvest drop evaluation is necessary. Alternatively, HLB may bring out changes in endogenous hormone homeostasis (Martinelli et al., 2012; Nehela et al., 2018) or carbohydrate levels (Rosales and Burns, 2011) during fruit developmental stages that affect fruit growth through suppressing cell division and/ or expansion that leads to their high likeliness to abscise at maturity.

\section{Conclusions}

The results of this research demonstrated that the size of citrus fruit is one of the few attributes that are consistently related to the incidence of mature fruit abscission and HLB symptom levels, indicating, for the first time, a link between fruit size and mature fruit drop in a manner depending on HLB severity. This further suggests that increased fruit drop at maturity is likely a consequence of suppression of fruit growth in HLB-affected trees. Hence, clarification of the physiological mechanism underlying how HLB influences cell division and enlargement during early fruit development is beneficial for the generation of strategies to mitigate elevated fruit drop in citrus. The results also suggest increasing fruit size may be a key to manage HLB-associated mature fruit drop. It has been reported that synthetic auxin and gibberellic acid that effectively prevent fruit drop in healthy trees had no noticeable effect on reducing the preharvest drop rate in HLBaffected citrus trees when applied in late fall ( $\approx 5-6$ months after bloom) (Albrigo and Stover, 2015). Nevertheless, plant hormones associated with cell division and cell expansion, such as cytokinin and auxin (Ferrer et al., 2017; Guardiola et al., 1993; Talon et al., 1997), may be used during initial fruit set to enhance fruit size and thereby increase their retention rate through harvest in trees affected by HLB. Meanwhile, CLas-caused impaired root system can result in altered water dynamics, thereby limiting fruit growth during the early development stage and increasing the tendency of trees to undergo stresses during the preharvest period. In this regard, preventing any stress condition for HLB-affected citrus trees, particularly water deficiency, is of importance to control mature fruit abscission as well as to maintain tree health for sustainable fruit production in the presence of HLB.

\section{Literature Cited}

Achor, D.S., E. Exteberria, N. Wang, S.Y. Folimonova, K.-R. Chung, and L.G. Albrigo. 2010. Sequence of anatomical symptom observations in citrus affected with Huanglongbing disease. Plant Pathol. J. 9:56-64.

Albrigo, L.G. and E.W. Stover. 2015. Effect of plant growth regulators and fungicides on Huanglongbing-related preharvest fruit drop of citrus. HortTechnology 25:785-790.

Alvarez, S., E. Rohrig, D. Solís, and M.H. Thomas 2016. Citrus greening disease (Huanglongbing) in Florida: Economic impact, management and the potential for biological control. Agr. Res. 5:109 118.
Baldwin, E., A. Plotto, J. Bai, J. Manthey, W. Zhao, S. Raithore, and M. Irey. 2018. Effect of abscission zone formation on orange (Citrus sinensis) fruit/juice quality for trees affected by Huanglongbing (HLB). J. Agr. Food Chem. 66:2877-2890.

Baldwin, E., A. Plotto, J. Manthey, G. McCollum, J. Bai, M. Irey, R. Cameron, and G. Luzio. 2010. Effect of Liberibacter infection (Huanglongbing Disease) of citrus on orange fruit physiology and fruit/fruit juice quality: Chemical and physical analyses. Agr. Food Chem. 58:1247-1262.

Bangerth, K.F. 2009. Floral induction in mature, perennial angiosperm fruit trees: Similarities and discrepancies with annual/biennial plants and the involvement of plant hormones. Scientia Hort. 122:153-163.

Bové, J.M. 2006. Huanglongbing: A destructive, newly emerging, century-old disease of citrus. J. Plant Pathol. 88:7-37.

Coggins, C.W. 1986. Fruit development and senescence: Citrus flowering, fruit set and development. March, Lake Alfred, FL.

Crane, J.C. 1964. Growth substances in fruit setting and development. Annu. Rev. Plant Physiol. 15:303-326.

Deng, H., D. Achor, E. Exteberria, Q. Yu, D. Du, D. Stanton, G. Liang, and F.G. Gmitter, Jr. 2019. Phloem regeneration is a mechanism for Huanglongbing-tolerance of "Bearss" lemon and "LB8-9" Sugar Belle ${ }^{\circledR}$ mandarin. Front. Plant Sci. 10, doi: 10.3389/fpls.2019.00277.

Easlon, H.M. and A.J. Bloom. 2014. Easy leaf area: Automated digital image analysis for rapid and accurate measurement of leaf area. Appl. Plant Sci. 2:1400033.

Etxeberria, E., P. Gonzalez, D. Achor, and G. Albrigo. 2009. Anatomical distribution of abnormally high levels of starch in HLB-affected Valencia orange trees. Physiol. Mol. Plant Pathol. 74:76-83.

Fan, X., H. Hu, G. Huang, F. Huang, Y. Li, and J. Palta. 2015. Soil inoculation with Burkholderia sp. LD-11 has positive effect on water-use efficiency in inbred lines of maize. Plant Soil 390:337-349.

Ferguson, L. and E.E. Grafton-Cardwell. 2014. Citrus production manual. Univ. of California, Agr. Natural Resources, Oakland, CA.

Ferrer, C., J. Martiz, S. Saa, and R. Cautín. 2017. Increase in final fruit size of tangor (Citrus reticulata $\times C$. sinensis) $\mathrm{cv}$ W. Murcott by application of benzyladenine to flowers. Scientia Hort. 223:38-43

Folimonova, S.Y., C.J. Robertson, S.M. Garnsey, S. Gowda, and W.O. Dawson. 2009. Examination of the responses of different genotypes of citrus to Huanglongbing (citrus greening) under different conditions. Phytopathology 99:1346-1354.

García-Tejero, I., R. Romero-Vicente, J.A. JiménezBocanegra, G. Martínez-García, V.H. DuránZuazo, and J.L. Muriel-Fernández. 2010. Response of citrus trees to deficit irrigation during different phenological periods in relation to yield, fruit quality, and water productivity. Agric. Water Manage. 97:689-699.

Gasque, M., P. Martí, B. Granero, and P. GonzálezAltozano. 2016. Effects of long-term summer deficit irrigation on 'Navelina' citrus trees. Agr. Water Mgt. 169:140-147.

Gavet, O. and J. Pines. 2010. Progressive activation of CyclinB1-Cdk1 coordinates entry to mitosis. Dev. Cell 18:533-543.

Ginestar, C. and J.R. Castel. 1996. Responses of young Clementine citrus trees to water stress during different phenological periods. J. Hort. Sci. 7:551-559. 
Goldschmidt, E.E. 1999. Carbohydrate supply as a critical factor for citrus fruit development and productivity. HortScience 34:1020-1024.

Goldschmidt, E.E. and S.P. Monselise. 1977. Physiological assumptions toward the development of a citrus fruiting model. Proc. Intl. Soc. Citrucult. 2:668-672.

Gómez-Cadenas, A., J. Mehouachi, F.R. Tadeo, E. Primo-Millo, and M. Talon. 2000. Hormonal regulation of fruitlet abscission induced by carbohydrate shortage in citrus. Planta 210:636-643.

Goren, R. and M. Huberman. 1976. Effects of ethylene and 2,4-D on the activity of cellulase isoenzymes in abscission zones of the developing orange fruit. Physiol. Plant. 37:123-130.

Graham, J.H., E.G. Johnson, T.R. Gottwald, and M.S. Irey. 2013. Presymptomatic fibrous root decline in citrus trees caused by Huanglongbing and potential interaction with Phytophthora spp. Plant Dis. 97:1195-1199.

Gu, F., M. Bringmann, J.R. Combs, J. Yang, D.C. Bergmann, and E. Nielsen. 2016. Arabidopsis CSLD5 functions in cell plate formation in a cell cycle-dependent manner. Plant Cell 28:1722-1737.

Guardiola, J.L., M.T. Barrés, C. Albert, and A. Garcila-Louis. 1993. Effects of exogenous growth regulators on fruit development in Citrus unshiu. Ann. Bot. 71:169-176.

Halbert, S.E. 2005. The discovery of Huanglongbing in Florida, p. H-3. In: Proc. 2nd Intl. Citrus Canker and Huanglongbing Research Workshop. Florida Citrus Mutual, Orlando, FL.

Halbert, S.E., C.L. Niblett, K.L. Manjunath, R.F. Lee, and L.G. Brown. 2000. Establishment of two new vectors of citrus pathogens in Florida. Proc. Intl. Soc. Citrucult. IX Congr. 1016-1017.

Hamido, S.A., K.T. Morgan, and D.M. Kadyampakeni. 2017. The effect of Huanglongbing on young citrus tree water use. Hort Technology 27:659665 .
Iglesias, D.J., M. Cercós, J.M. Colmenero-Flores, M.A. Naranjo, G. Ríos, E. Carrera, O. RuizRivero, I. Lliso, R. Morillon, F.R. Tadeo, and M. Talon. 2007. Physiology of citrus fruiting. Braz. J. Plant Physiol. 19:333-362.

Jagoueix, S., J.-M. Bové, and M. Garnier. 1994 The phloem-limited bacterium of greening disease of citrus is a member of the $\alpha$ subdivision of the proteobacteria. Intl. J. Syst. Bacteriol. 44:379-386.

Johnson, E.G., J. Wu, D.B. Bright, and J.H. Graham. 2014. Association of 'Candidatus Liberibacter asiaticus' root infection, but not phloem plugging with root loss on Huanglongbing-affected trees prior to appearance of foliar symptoms. Plant Pathol. 63:290-298.

Kim, J.-S., U.S. Sagaram, J.K. Burns, J.-L. Li, and N. Wang. 2008. Response of sweet orange (Citrus sinensis) to 'Candidatus Liberibacter asiaticus' infection: Microscopy and microarray analyses. Phytopathology 99:50-57.

Liao, H.-L. and J.K. Burns. 2012. Gene expression in Citrus sinensis fruit tissues harvested from Huanglongbing-infected trees: Comparison with girdled fruit. J. Expt. Bot. 63:33073319.

Martinelli, F., S.L. Uratsu, U. Albrecht, R.L. Reagan, M.L. Phu, M. Britton, V. Buffalo, J. Fass, E. Leicht, W. Zhao, D. Lin, R. D’Souza, C.E. Davis, K.D. Bowman, and A.M. Dandekar. 2012. Transcriptome profiling of citrus fruit response to Huanglongbing disease. PLoS One 7:e38039.

Nehela, Y., F. Hijaz, A.A. Elzaawely, H.M. ElZahaby, and N. Killiny. 2018. Citrus phytohormonal response to Candidatus Liberibacter asiaticus and its vector Diaphorina citri. Physiol. Mol. Plant Pathol. 102:24-35.

Pérez-Pérez, J.G., J.M. Robles, and P. Botía. 2009. Influence of deficit irrigation in phase III of fruit growth on fruit quality in 'Lane Late' sweet orange. Agr. Water Mgt. 96:969-974.
Romero, P., J.M. Navarro, J. Pérez-Pérez, F. García-Sánchez, A. Gómez-Gómez, I. Porras, V. Martinez, and P. Botía. 2006. Deficit irrigation and rootstock: Their effects on water relations, vegetative development, yield, fruit quality and mineral nutrition of Clemenules mandarin. Tree Physiol. 26:1537-1548.

Rosales, R. and J.K. Burns. 2011. Phytohormone changes and carbohydrate status in sweet orange fruit from Huanglongbing-infected trees. J. Plant Growth Regul. 30:312-321.

Ruiz, R., A. García-Luis, C. Monerri, and J.L. Guardiola. 2001. Carbohydrate availability in relation to fruitlet abscission in citrus. Ann. Bot. 87:805-812.

Ruzin, S.E. 1999. Plant microtechnique and microscopy. Oxford Univ. Press, New York, NY.

Schneider, C.A., W.S. Rasband, and K.W. Eliceiri. 2012. NIH Image to Image J: 25 years of image analysis. Nat. Methods 9:671-675.

Slinski, S. 2016. Evaluation of HLB treatments. Citrus Industry. August 2016:10-12.

Spann, T.M. and W.C. Oswalt. 2008. Citrus greening effects on fruit size distribution and yield in citrus trees. Proc. Florida State Hort. Soc. 121:97-99.

Syvertsen, J.P. and L.G. Albrigo. 1980. Seasonal and diurnal citrus leaf and fruit water relations. Bot. Gaz. 141:440-446.

Talon, M., F.R. Tadeo, W. Ben-Cheikh, A. GomezCadenas, J. Mehouachi, J. Pérez-Botella, and E. Primo-Millo. 1997. Hormonal regulation of fruit set and abscission in citrus: Classical concepts and new evidence. Acta Hort. 463:209-218.

Tang, L., S. Chhajed, and T. Vashisth. 2019. Preharvest fruit drop in Huanglongbingaffected 'Valencia' sweet orange. J. Amer. Soc. Hort. Sci. 144:107-117.

U.S. Department of Agriculture (USDA). 2019 Florida citrus fruit size and drop, 2018-19 report. Dept. Agr., Washington, D.C. 

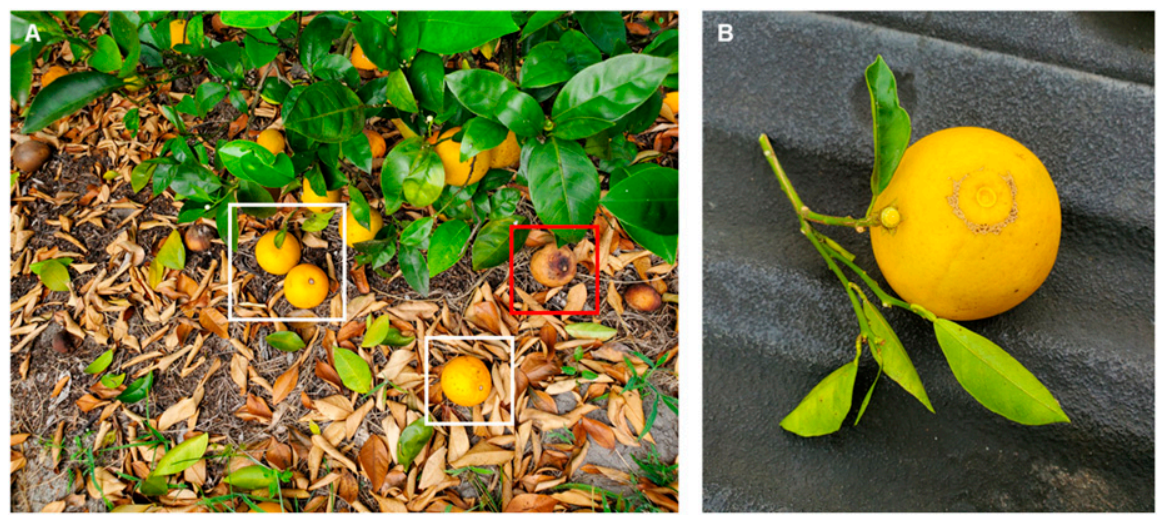

Supplemental Fig. 1. Dropped fruit of Huanglongbing (HLB)-affected 'Hamlin' sweet orange before harvest. On the orchard floor (A), white squares indicate the fruit that dropped due to HLB-associated physiological abscission (without stem-end rot), whereas a dropped fruit with stem-end rot, which is possibly because of the secondary infection of another pathogen, is indicated by the red square. A close-up of the dropped fruit during the physiological abscission associated with HLB is illustrated (B).
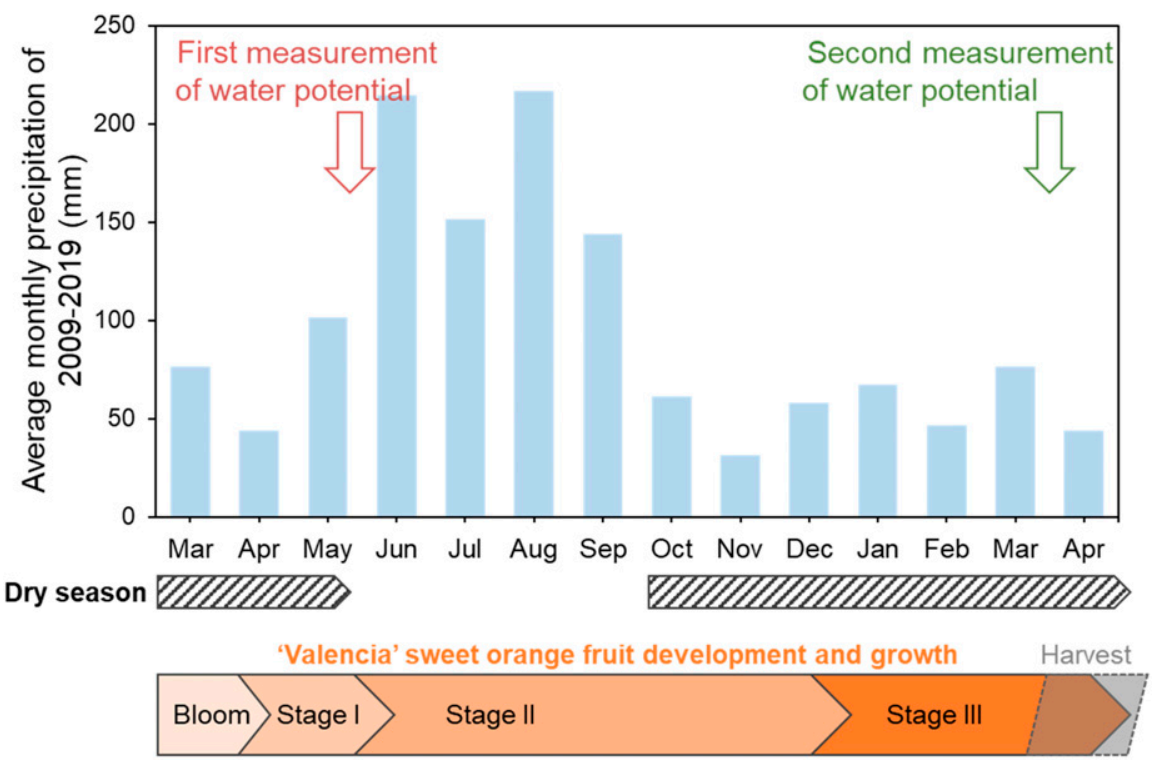

Bloom >

Supplemental Fig. 2. The average monthly precipitation of the last decade (2009-19), with an overview of flowering and fruit development stages in 'Valencia' sweet orange. The red and green arrows indicate the times of the first and second water potential measurement, respectively, in this study. 